\title{
Biogas dry reforming over Ni-Ce catalyst supported on nanofibered alumina
}

\author{
J.J. González, J.F. Da Costa-Serra, A. Chica* \\ Instituto de Tecnología Química (Universitat Politècnica de València-Consejo Superior de \\ Investigaciones Científicas), Avd. de los Naranjos s/n, 46022 Valencia (Spain). \\ *Corresponding author. Tel.: +34 9638770 00-78508; fax: +34 963877809 . \\ E-mail address: achica@itq.upv.es
}

\begin{abstract}
Four catalysts based on $\mathrm{Ni}$ and Ni-Ce supported on two $\gamma$-aluminas with different morphology (nanofibers and nanograins) have been prepared and studied in the dry reforming of simulated biogas. Catalysts were characterized by $\mathrm{N}_{2}$ physisorption, X-ray diffraction (XRD), temperature-programmed reduction (TPR), transmission electron microscopy (TEM), scanning electron microscopy (SEM), inductively coupled plasma with optical emission spectrometer (ICP-OES), chemisorption of $\mathrm{H}_{2}$ and elemental analysis (EA) to determine their most relevant physicochemical properties. Characterization results show that metallic $\mathrm{Ni}$ particles supported on nanofibered alumina (NFA) presents a higher dispersion and smaller size than that supported on the nanograiny alumina (NGA) probably due to the higher mesoporosity presented by the NFA support. On the other hand, the incorporation of Ce has a similar effect than the fibrous morphology, decreasing also the size of the Ni metallic particles and increasing their dispersion. In the dry reforming of synthetic biogas $\left(\mathrm{CH}_{4} / \mathrm{CO}_{2}=1.5\right)$ the nanofibered alumina containing 5 wt.\% $\mathrm{Ni}$ and 1.5 wt.\% Ce (NiCe/NFA) showed the highest catalytic activity at $750{ }^{\circ} \mathrm{C}\left(98 \% \mathrm{CO}_{2}\right.$ conversion) and stability $(7.7 \%$ nickel sinterization level and 2.9 wt.\% carbon deposition). The stability of this catalyst was also demonstrated at $750{ }^{\circ} \mathrm{C}$ during $55 \mathrm{~h}$ of reaction time with a loss of activity at the steady state under $2 \%$. In addition, the catalyst was regenerated at $600{ }^{\circ} \mathrm{C}$ in oxygen flow, recovering completely its initial catalytic performance. The excellent catalytic behavior of NiCe/NFA material has been related to the fibrous morphology of the alumina support, which promotes a better dispersion of the supported Ni metal particles, decreasing their size and increasing the number of actives sites where dry reforming reaction can take place. In addition, the incorporation of $\mathrm{Ce}$ seems to have also an important role by increasing the Ni-support interactions, decreasing sinterization of the metallic Ni particles and coke deposition. The contribution of both effects (morphology and Ce), separately and in combination, have been proved to enhance significantly the catalytic activity and stability of the synthesized catalysts in the dry reforming of simulated biogas.
\end{abstract}

Keywords: Dry reforming, nanofibered alumina, nickel and cerium catalysts, $\mathrm{H}_{2}$ production, syngas, biogas.

\section{Introduction.}

The interest to develop renewable fuels to alleviate important problems of our current energetic system, such us the scarcity of fossil fuels and the emission of pollutants, is in continuous growing. Renewable energy target in the European Union for 2020 is expected to achieve from bioenergy, among which at least $25 \%$ will be biogas [1]. Thus, biogas, among other renewable biofuels, represents an attractive renewable carbon source and its exploitation would be advantageous from both financial and environmental points of view. Biogas can be produced by fermentation processes or anaerobic digestion of organic waste coming from different sources such as sewage, sludge, landfill or industry [2]. It is mainly composed of $\mathrm{CH}_{4}, \mathrm{CO}_{2}$ and minor species such as sulphur, nitrogen or water, varying the composition according to the starting substrate [2-4]. Thus, dry reforming of biogas (Eq. (1)) would be interesting processes to produce synthesis gas [5]. The high levels of $\mathrm{CO}_{2}(45-75 \%)$ and $\mathrm{CH}_{4}(55-75 \%)$ enable the conversion of biogas to synthesis 
gas ( $\mathrm{CO}$ and $\mathrm{H}_{2}$, syngas) by dry reforming, avoiding the high cost of the purification process to separate $\mathrm{CO}_{2}$ from $\mathrm{CH}_{4}$. Thus, biogas dry reforming has recently emerged as an attractive technological solution that would eradicate the need for $\mathrm{CO}_{2}$ removal from biogas and its release to the atmosphere. On the other hand, produced syngas is a crucial intermediate to produce hydrogen, ammonia, methanol, and synthetic hydrocarbon fuels. Thus, liquid biofuels can be produced by biogas dry reforming to produce syngas, and the subsequent Fischer-Tropsch process to produce biofuels in the selected range (gasoline, diesel or jet) [6].

$$
\mathrm{CO}_{2}+\mathrm{CH}_{4} \leftrightarrow 2 \mathrm{CO}+2 \mathrm{H}_{2} \quad\left(\Delta \mathrm{H}^{\mathrm{o}}{ }_{298}=+247 \mathrm{~kJ} / \mathrm{mol}\right)
$$

Methane dry reforming is a highly endothermic reaction, which takes place at high reaction temperatures (800-1000 ${ }^{\circ} \mathrm{C}$ ). Carbon deposition can easily occur at that high temperatures according to the Eqs. (2), (3) and (4), covering the catalyst active sites and reduces the activity of catalyst significantly [7].

$$
\begin{array}{ll}
2 \mathrm{CO} \rightarrow \mathrm{C}+\mathrm{CO}_{2} & \left(\Delta \mathrm{H}^{\mathrm{o}}{ }_{298}=-171 \mathrm{~kJ} / \mathrm{mol}\right) \\
\mathrm{CH}_{4} \rightarrow \mathrm{C}+2 \mathrm{H}_{2} & \left(\Delta \mathrm{H}^{\mathrm{o}}{ }_{298}=+75 \mathrm{~kJ} / \mathrm{mol}\right) \\
\mathrm{CO}+\mathrm{H}_{2} \rightarrow \mathrm{C}+\mathrm{H}_{2} \mathrm{O} & \left(\Delta \mathrm{H}^{\mathrm{o}}{ }_{298}=-131 \mathrm{~kJ} / \mathrm{mol}\right)
\end{array}
$$

An important problem related to the dry reforming reaction of methane is the coke generation, one of the main reason why this reaction has not yet been commercialized [8-11]. Catalyst nature clearly affects the coke formation rate, so current research efforts have focused on developing highly stable catalysts with low carbon production [12-16]. Among them, nickel based catalysts have attracted interest due to their lower cost and higher availability compared with noble metal catalysts, and also by its significant intrinsic activity, especially when the $\mathrm{Ni}$ is highly dispersed on the support [17-34]. However, as already mentioned, they suffer deactivation due to carbon formation and sinterization of metallic particles, due to a lack of adequate thermal stability $[35,36]$. In addition, catalyst support has also an important role since it can help to stabilize the metallic particles through efficient interactions support-metallic particles, decreasing the coke formation and the sinterization of the metallic particles [37-39]. Together with the nature of the support, its morphology has been also reported that can modify the size and dispersion of the supported metallic particles, improving their catalytic performance via low coke formation and metal sinterization $[39,40]$. On the other hand, the incorporation of metals as Ce in Ni-based catalysts has been also reported that can increase the stability during the dry reforming reaction [41-46]. Specifically, it has been reported that formation of cerium aluminate phase $\left(\mathrm{CeAlO}_{3}\right)$ enhances significantly the catalyst resistance to carbon deposition, while dry reforming activity is retained. Cerium aluminate shows ability for decomposing $\mathrm{CO}_{2}$ to form active surface oxygen, minimizing deactivation by carbon deposition [47]. Also the presence of Ce helps to increase the metallic nickel dispersion with strong metal-support interactions, retaining the small Ni particles size and improving the stability of these particles against sintering at the same time that the growing of carbon whiskers is inhibited [48].

In this paper is showed by the first time the individual and combined effect of the morphology of the support and Ce presence in the development of Ni-based catalysts with high activity and stability in the dry reforming of methane. Ni supported on un-promoted and promoted with $\mathrm{CeO}_{2}$ alumina catalysts have been prepared using two alumina supports with different morphology (nanograins and nanofibers). The catalysts were characterized by different techniques to know their most relevant physicochemical properties and tested at different temperatures in the dry reforming of a simulated biogas. To assess our catalyst in more realistic biogas applications, a typical range of $\mathrm{CH}_{4} / \mathrm{CO}_{2}$ of 1.5 was applied. The experimental results demonstrated that support morphology, together Ce presence, have a positive effect in the preparation of high active and stable catalysts in the dry reforming of methane by decreasing coke deposition and sinterization of supported metallic nickel significantly.

\section{Experimental.}

\subsection{Preparation of catalyst.}

Nanofibered alumina (NFA) was prepared by sol-gel method. Aluminium isopropoxide (98\%, Strem Chemicals), acetic acid (99\%, Sigma-Aldrich) and 2-propanol (99.5\%, Fisher) were used as starting 
materials for the synthesis of nanofibered alumina. Aluminium isopropoxide was dissolved in 2-propanol and Milli-Q water with continuous stirring at $80{ }^{\circ} \mathrm{C}$ for few minutes. Then, the other solution containing acetic acid and Milli-Q water was slowly added and the obtained gel was stirred at $80^{\circ} \mathrm{C}$ for 20 hours under reflux. The final precipitate was filtered, washed with 2-propanol and dried at $80{ }^{\circ} \mathrm{C}$ for 12 hours. The obtained solid was calcined at $750{ }^{\circ} \mathrm{C}$ for 4 hours, to obtain the nanofibered alumina (NFA).

Nanograiny alumina (NGA) was a commercial $\gamma$-Alumina provided by Strem Chemicals ( $\gamma$-Alumina, 97\%).

Nickel and cerium were incorporated in the nanofibered and nanograiny alumina by incipient wetness impregnation method with an aqueous solution containing the required amount of $\mathrm{Ni}\left(\mathrm{NO}_{3}\right)_{2} \cdot 6 \mathrm{H}_{2} \mathrm{O}$ and $\mathrm{Ce}\left(\mathrm{NO}_{3}\right)_{3} \cdot 6 \mathrm{H}_{2} \mathrm{O}$ (supplied by Sigma Aldrich, $98.5 \%$ and $99 \%$ respectively) to obtain a nickel and cerium contain of $5 \mathrm{wt} . \%$ and $1.5 \mathrm{wt} . \%$, respectively. After impregnation, the samples were dried overnight at 100 ${ }^{\circ} \mathrm{C}$ and then they were calcined in a muffle furnace for 3 hours at $400{ }^{\circ} \mathrm{C}(\mathrm{Ni} / \mathrm{NGA}, \mathrm{NiCe} / \mathrm{NGA}, \mathrm{Ni} / \mathrm{NFA}$ and $\mathrm{NiCe} / \mathrm{NFA}$ ).

\subsection{Characterization techniques.}

The catalysts used in this study have been subjected to inductively coupled plasma with optical emission spectrometer (ICP-OES) in a Varian 700-ES Series to determine the amount of Ni and Ce incorporated.

Textural properties (BET area and pore volume) were measured using an ASAP 2420 apparatus (Micromeritics) at $77 \mathrm{~K}$. Before the analysis, $200 \mathrm{mg}$ of each pelletized sample $(0.25-0.40 \mathrm{~mm})$ were degassed at $673 \mathrm{~K}$ with high vacuum $(\sim 5 \times 10-6$ bar) overnight. The BET surface area was calculated by using the Brunauer-Emmett-Teller equation, micropore volume was calculated by the t-plot method.

X-ray diffraction (XRD) has been carried out to identify the crystalline phases present in each catalyst. Measurements were carried out at room temperature in a Panalytical CubiX diffractometer using $\mathrm{CuK} \alpha$ radiation. The identification of the crystalline phases has been carried out using the X'Pert HighScore Plus software.

Temperature programmed reduction (TPR) were carried out to study the reduction properties of supported nickel. Measurements were carried out in a Micromeritics Autochem 2910 equipment. Between 30 and 100 $\mathrm{mg}$ of sample, in the granulometry $0.25-0.40 \mathrm{~mm}$ were loaded in a quartz U-tube, a fixed bed between quartz wool. Samples were treated in Ar flow at room temperature for 30 minutes and then the circulating gas was replaced with $10 \% \mathrm{H}_{2}(\mathrm{vol}) / \mathrm{Ar}(50 \mathrm{~mL} / \mathrm{min})$ and the temperature was increased from room temperature to $1173 \mathrm{~K}$ at a rate of $10 \mathrm{~K} / \mathrm{min}$. Downstream of the reactor, a 2-propanol $/ \mathrm{N}_{2}(1)$ trap was placed to retain the water formed in the reductions, and $\mathrm{H}_{2}$ consumption was recorded on a thermal conductivity detector (TCD), previously calibrated using the reduction of $\mathrm{CuO}$ as a reference.

The amount of carbon deposited in the catalysts after reaction was determined by elemental analysis using a Carlo Erba 1106 analyzer.

The morphology of alumina support and the size of the nickel metallic particles were studied by transmission electron microscopy (TEM) using a JEOL-JEM2100F microscope.

The morphology of catalysts was also studied by scanning electron microscopy (SEM) using a JEOLJSM6300 microscope.

The active metallic surface area (AMSA) was estimated from $\mathrm{H}_{2}$ adsorption using the double isotherm method on a Quantachrome Autosorb-1 equipment. Prior to adsorption, the samples (ca. $0.3 \mathrm{~g}$ ) were pretreated in flowing $\mathrm{He}$ at $393 \mathrm{~K}$ for $1 \mathrm{~h}$ and then reduced in situ by flowing pure $\mathrm{H}_{2}$ at $973 \mathrm{~K}$ for $3 \mathrm{~h}$. After reduction, the samples were degassed and cooled to $373 \mathrm{~K}$ to register the adsorption isotherm.

\subsection{Catalytic study.}

Dry reforming of simulated biogas $\left(\mathrm{CH}_{4} / \mathrm{CO}_{2}=1.5 \mathrm{~mol} / \mathrm{mol}\right)$ was performed in a continuous fixed bed reactor at atmospheric pressure, GHSV of $1000 \mathrm{~h}^{-1}$ and a range of temperatures between 600 and $900{ }^{\circ} \mathrm{C}$. Before setting up the reaction, the catalysts were reduced "in situ" in $\mathrm{H}_{2}$ flow at $700{ }^{\circ} \mathrm{C}$ during $2 \mathrm{~h}$. Afterwards, simulated biogas was fed into the reactor. The gas products were analyzed using an online gas 
chromatograph Bruker 450-GC equipped with two detectors (TCD and FID) and three columns (Carbosieve S-II, Hayesep Q and Hayesep T).

$\mathrm{CO}_{2}$ and $\mathrm{CH}_{4}$ conversion and $\mathrm{H}_{2} / \mathrm{CO}$ ratio were determined according to the Eqs. (5), (6) and (7), where $\mathrm{F}_{\mathrm{CH} 4 \text {,in }}$ and $\mathrm{F}_{\mathrm{CO} 2 \text {,in }}$ are the molar flow rate of $\mathrm{CH}_{4}$ and $\mathrm{CO}_{2}$ at the reactor inlet and $\mathrm{F}_{\mathrm{CH} 4 \text {,out }}$ and $\mathrm{F}_{\mathrm{CO} 2 \text {,out }}$ are the molar flow rate of $\mathrm{CH}_{4}$ and $\mathrm{CO}_{2}$ at the reactor outlet.

$$
\begin{aligned}
& X_{\mathrm{CH} 4}(\%, \mathrm{~mol})=\frac{F_{C H 4, \text { in }}-F_{\mathrm{CH} 4, \text { out }}}{F_{\mathrm{CH} 4 \text {,in }}} \times 100 \\
& X_{\mathrm{CO} 2}(\%, \mathrm{~mol})=\frac{F_{\mathrm{CO} 2 \text {, in }}-F_{\mathrm{CO} 2, \text { out }}}{F_{\mathrm{CO} 2, \text { in }}} \times 100 \\
& \frac{\mathrm{H}_{2}}{\mathrm{CO}} \text { ratio }=\frac{\text { moles of } \mathrm{H}_{2} \text { produced }}{\text { moles of } \mathrm{CO} \text { produced }}
\end{aligned}
$$

\section{Results and discussion.}

\subsection{Supports and catalysts characterization.}

Characterization by X-ray diffraction (XRD) has been carried out to identify the crystalline phases present in the studied catalysts. X-ray diffraction patterns of catalysts and their corresponding alumina supports are shown in Figure 1a and 1b. As it can be seen diffraction peaks corresponding to Ni or Ce phases are not detected in any of the two series of catalysts. The observed diffraction peaks can be attributed to the alumina support and they are related to the aluminum oxide [JCPDS 00-001-1303] and aluminum oxide hydrate (Bayerite o Gibbsite) [JCPDS 00-001-0287] [49, 50]. This circumstance could be explained considering that: i) diffraction peaks of $\mathrm{Ni}$ and $\mathrm{Ce}$ oxides could be hid by the wide diffraction peaks of the alumina support [51, 52], ii) a high dispersion of $\mathrm{Ni}$ and Ce oxides is occurring, iii) percentage of $\mathrm{Ni}$ and $\mathrm{Ce}$ is very low to detect their corresponding phases, iv) the formation of other compounds such as $\mathrm{NiAl}_{2} \mathrm{O}_{4}$ and $\mathrm{CeAlO}_{3}$ could be ocurring, however these compounds present diffraction peaks at similar angles to those presented by alumina support, being very difficult to detect them when they are present in a low concentrations [53].
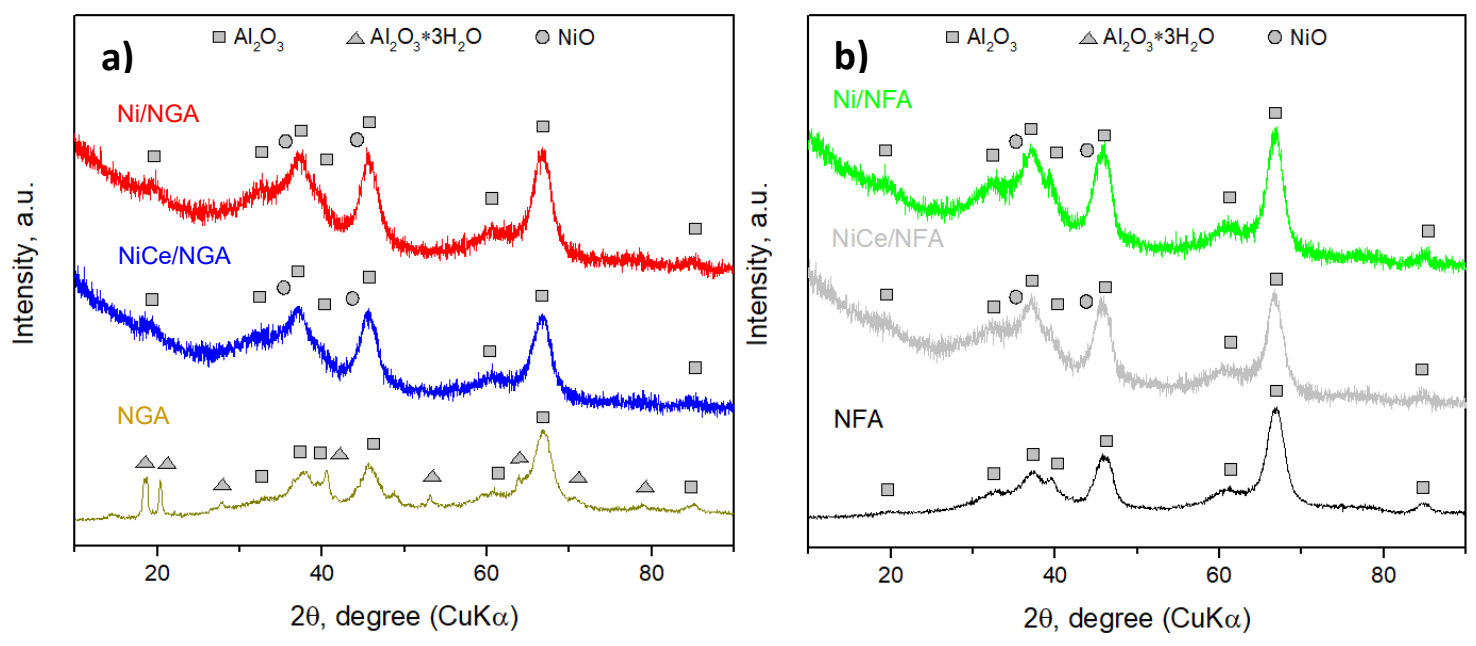

Figure 1. XRD of the different catalysts studied in this work. a) XRD of calcined Ni/NGA and NiCe/NGA catalysts and their corresponding NGA support. b) XRD of calcined Ni/NFA and NiCe/NFA catalysts and their corresponding NFA support.

The morphology of the alumina supports and their corresponding catalysts with $\mathrm{Ni}$ and $\mathrm{NiCe}$ has been also investigated by SEM (Figure 2) and TEM (Figure 3). As it can be seen in Figure 2 the NFA support has a 
more frayed appearance compared to NGA, due to its nanofibrated morphology. In general, the addition of $\mathrm{Ni}$ and NiCe to the supports and the subsequent calcination do not produce drastic changes in the appearance of the final catalysts, keeping the nanograiny and nanofibered morphologies similar to the original aluminas.
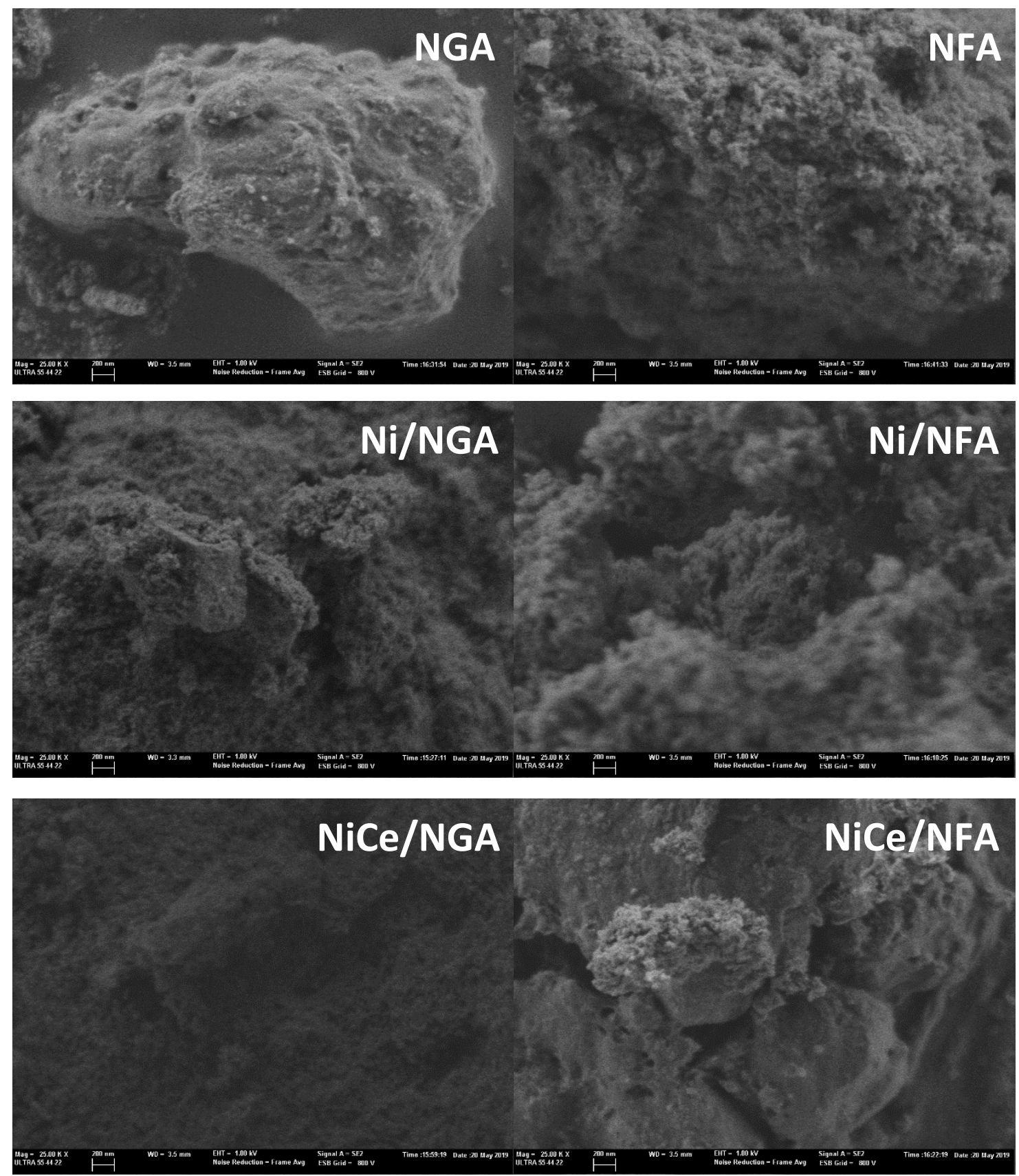

Figure 2. SEM images of calcined catalysts and their corresponding supports.

TEM images of calcined catalysts and their corresponding supports are showed in Figure 3. Now, the morphology differences between nanograiny and nanofibered alumina result more evident. Specifically, the NFA support is formed clearly by nanofibers while the NGA present "nanograins". It can be seen also that the incorporation of $\mathrm{Ni}$ and Ce does not vary in excess the TEM images for any of the catalysts as it was already found in the studies by SEM. 

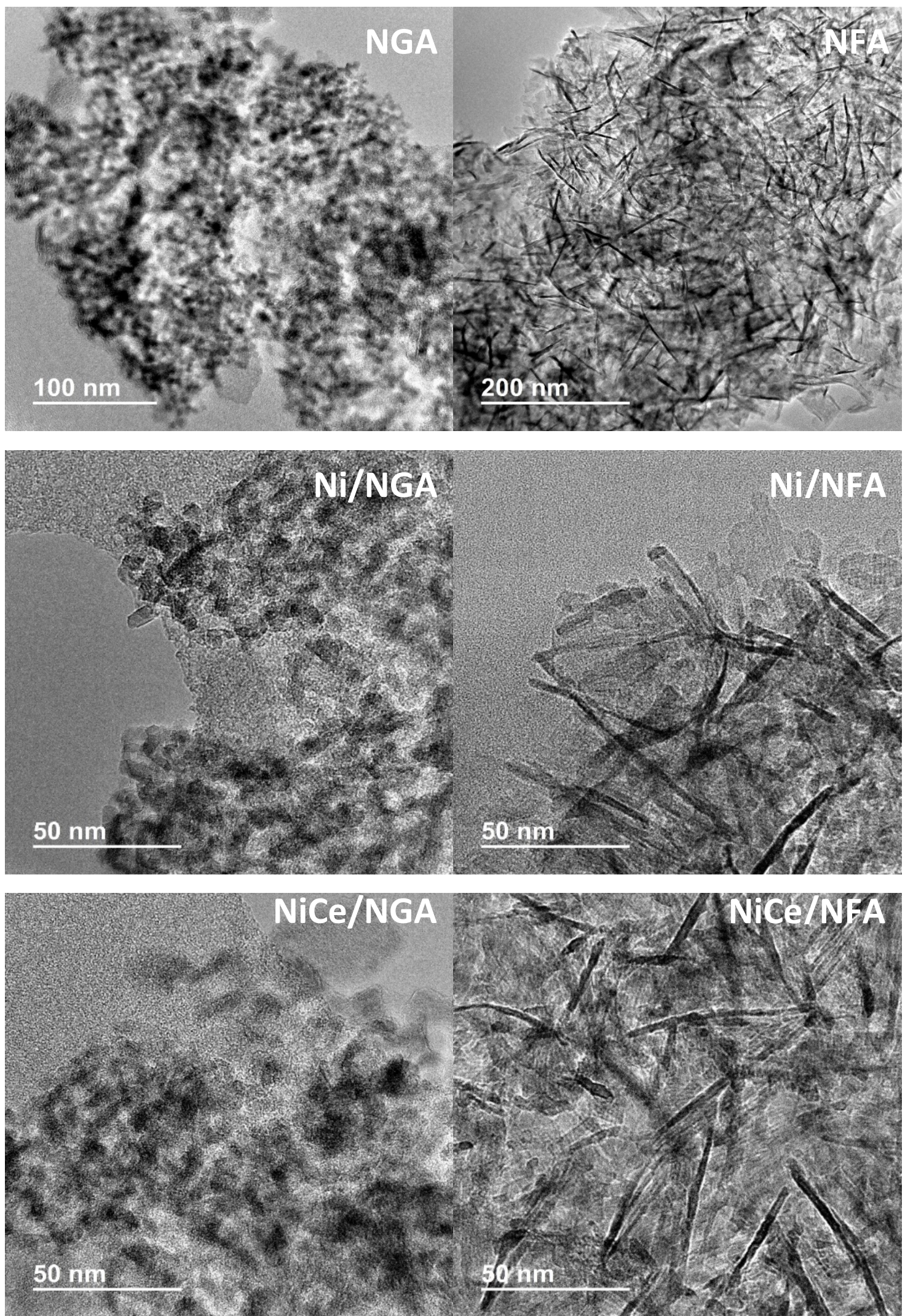

Figure 3. TEM images of calcined catalysts and their corresponding supports.

BET surface area, pore volume and metal content (Ce and $\mathrm{Ni}$ ) for the studied catalysts are showed in Table 1. As it can be seen levels of $\mathrm{Ni}$ between 5 and $6 \mathrm{wt} . \%$ has been determined for all the catalysts and 1.5 wt. \% of Ce for the samples containing this metal. In relation to the textural properties, a decreasing of BET surface area and pore volume can be observed when $\mathrm{Ni}$ and $\mathrm{Ce}$ are incorporated in the alumina supports. 
This fact could be explained considering a partial blockage of the alumina micropores by the nanoparticles of $\mathrm{NiO}$ and $\mathrm{CeO}_{2}$ formed during the calcination step [54-62]. In general, not significantly differences in the BET surface area is found for the four catalysts here studied.

Table 1. Ni and Ce content, BET surface area and pore volume for the catalysts studied in this work.

\begin{tabular}{lcccc}
\hline Sample & $\begin{array}{c}\text { BET surface area } \\
\left(\mathbf{m}^{2} / \mathbf{g}\right)\end{array}$ & $\begin{array}{c}\text { Pore vol. } \\
\left(\mathbf{m}^{\mathbf{3}} / \mathbf{g}\right)\end{array}$ & $\mathbf{N i}, \mathbf{w t . \%}$ & Ce, wt.\% \\
\hline NGA & 278 & 0.477 & - & - \\
NFA & 248 & 0.501 & - & - \\
Ni/NGA & 254 & 0.381 & 5.9 & - \\
NiCe/NGA & 242 & 0.373 & 5.8 & 1.4 \\
Ni/NFA & 234 & 0.488 & 5.2 & - \\
NiCe/NFA & 226 & 0.483 & 5.0 & 1.5 \\
\hline
\end{tabular}

Figure 4 shows adsorption/desorption isotherms and pore diameter distributions of the alumina supports studied in this work. NFA support shows an adsorption/desorption isotherm typical of a mesoporous material and also a higher average pore diameter compared to NGA support.
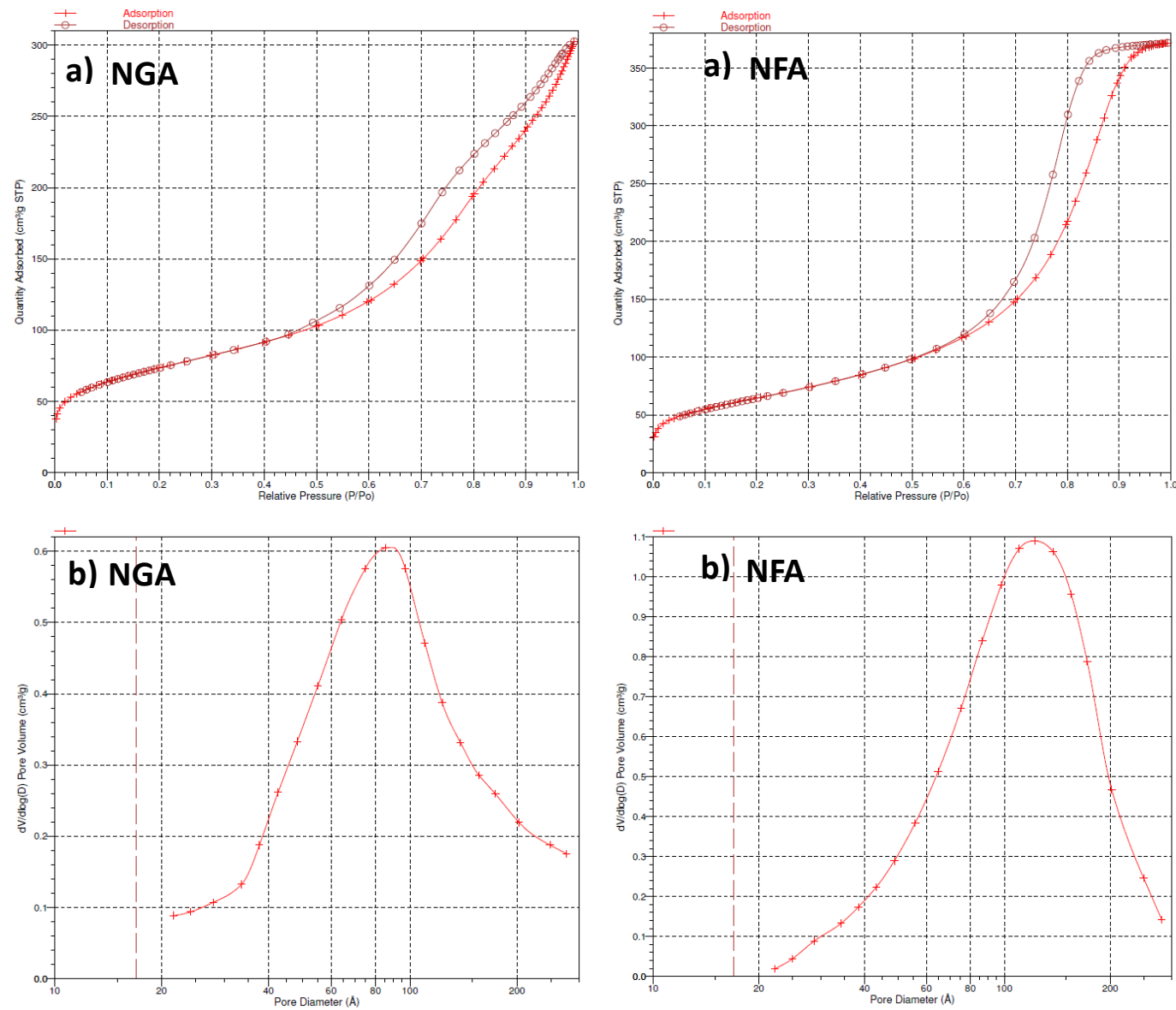

Figure 4. a) Adsorption/Desorption isotherms and b) pore diameters of the NGA and NFA supports.

Characterization of the reduced catalysts was also carried out. The XRD of the reduced catalysts is showed in Figure 5. Previously, XRD of the calcined catalysts showed only diffraction peaks corresponding to the alumina support, Figure 1. Now, together with the aluminum oxide phase [JCPDS 00-001-1303], corresponding to the alumina support, diffraction peaks corresponding to metallic nickel [JCPDS 03-0650380] can also be found. 

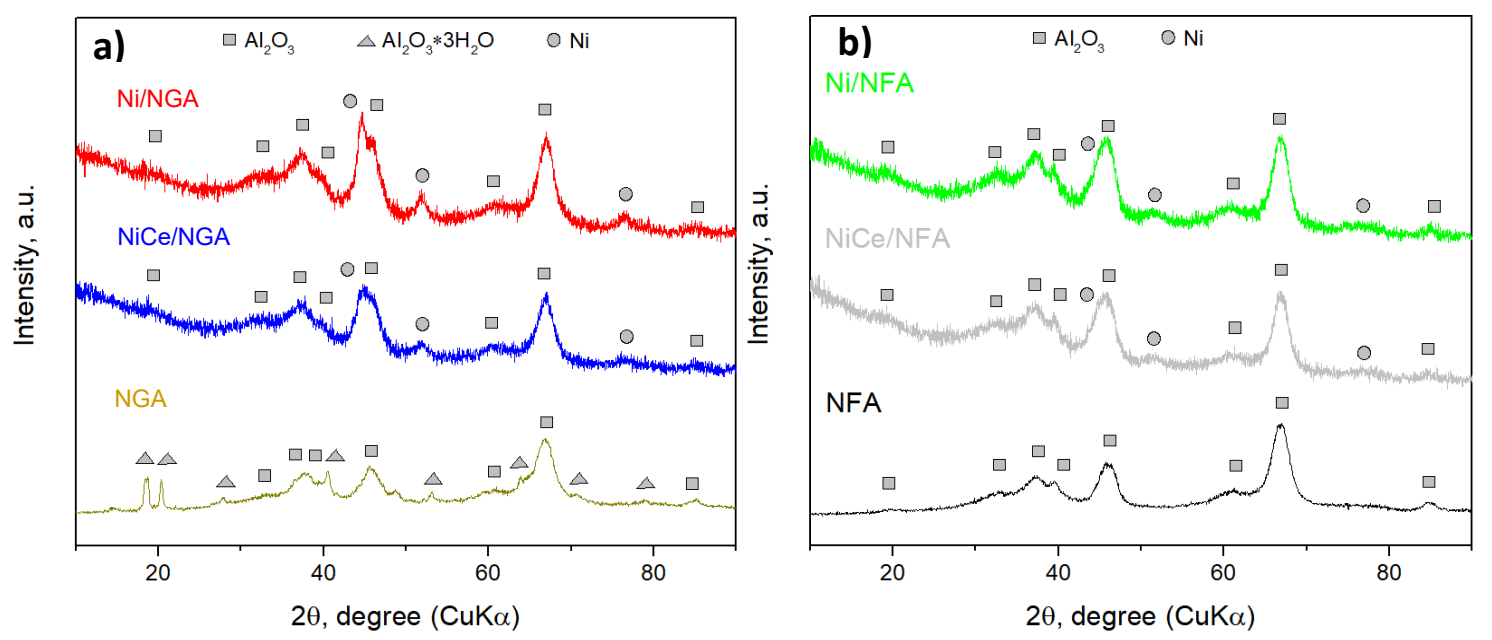

Figure 5. XRD of the different catalysts studied in this work. a) XRD of reduced Ni/NGA and NiCe/NGA catalysts and their corresponding NGA support. b) XRD of reduced Ni/NFA and NiCe/NFA catalysts and their corresponding NFA support.

The crystalline size of metallic nickel $\left(\mathrm{Ni}^{0}\right)$ has been determined from the XRD of the reduced catalysts, using the Scherrer equation [63]. As it can be seen in Table 2, when samples containing only Ni are compared (Ni/NGA and Ni/NFA), the metallic nickel supported on NFA (Ni/NFA) presents a smaller crystallite size than that supported on NGA (Ni/NGA) $(5.4$ and $7.7 \mathrm{~nm}$, respectively). This result seems to indicate that the nanofibered morphology would having a positive effect promoting the formation of $\mathrm{Ni}^{0}$ with smaller size. In the case of the $\mathrm{Ce}$, if the samples with and without $\mathrm{Ce}$ for the same alumina support are compared (Ni/NGA-NiCe/NGA and Ni/NFA-NiCe/NFA), it can be seen a similar effect than those found for the morphology, that is, the smallest size of $\mathrm{Ni}^{0}$ is found for the samples containing Ce. Finally, it can be seen that the smallest crystallite sizes correspond to the sample containing $\mathrm{Ni}$ and Ce supported on nanofibered alumina (NiCe/NFA, $3.9 \mathrm{~nm}$ ), where the effects of the morphology and Ce concurrent simultaneously.

Crystallite size of metallic nickel has been also determined by TEM. Figure 6 shows the TEM images of the reduced catalysts. Distribution frequencies of sizes have been also determined for each catalyst. As it can be seen, the same trend than those determined by XRD was found. Again, the smallest sizes were found for the sample containing $\mathrm{Ni}$ and Ce supported on nanofibered alumina. 

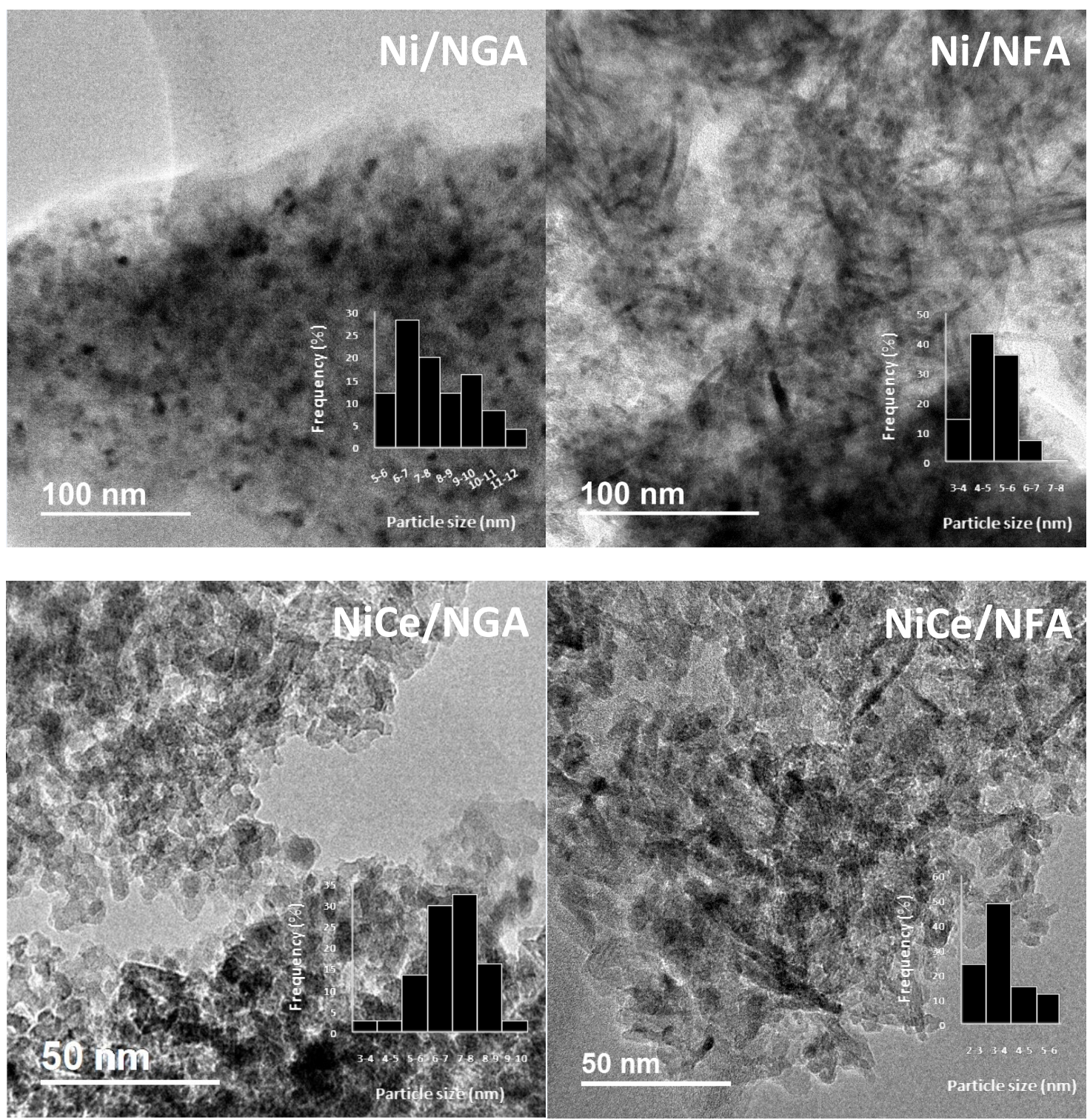

Figure 6. TEM images of reduced catalysts and their corresponding particle size distribution of metallic Ni.

Active metal surface area (AMSA) and dispersion of the metallic Ni particles have been also determined by $\mathrm{H}_{2}$-Chemisorpiton, Table 2 . Comparing the catalysts containing only $\mathrm{Ni}$ (Ni/NGA and Ni/NFA), it can be seen that catalyst prepared with NFA presents a larger active metal surface area, suggesting again that the nanofibered morphology could be promoting an improvement of the metallic nickel distribution and its accessibility. It is possible that the mesoporosity presented by the NFA support favor the diffusion of the metallic precursors during the impregnation step, improving the dispersion of the $\mathrm{Ni}$ and $\mathrm{Ce}$ in the final catalyst and explaining the lower size of the metallic particles detected in this support. On the other hand, the incorporation of $\mathrm{Ce}$ leads to an additional increasing in the active metal surface area, confirming the observation already reported in literature [48]. 
Table 2. Size of the metallic nickel particles determined by XRD and TEM, active metal surface area (AMSA) and metal dispersion determined by $\mathrm{H}_{2}$-Chemisorption and reducibility determined by TPR.

\begin{tabular}{lccccc}
\hline Sample & $\begin{array}{c}\mathbf{N i}^{\mathbf{0}}, \mathbf{X R D} \\
(\mathbf{n m})\end{array}$ & $\begin{array}{c}\mathbf{N i}^{\mathbf{0}}, \mathbf{T E M} \\
\mathbf{( n m )}\end{array}$ & $\begin{array}{c}\text { AMSA } \\
\left(\mathbf{m}^{2} / \mathbf{g}\right)\end{array}$ & Dispersion \% & $\begin{array}{c}\text { Reducibility \%o, } \\
\left.\mathbf{( 7 0 0}^{\mathbf{0}} \mathbf{C}\right)\end{array}$ \\
\hline Ni/NGA & 7.7 & 7.9 & 1.64 & 4.9 & 84 \\
NiCe/NGA & 7.3 & 6.5 & 1.79 & 5.4 & 81 \\
Ni/NFA & 5.4 & 4.3 & 2.50 & 7.5 & 73 \\
NiCe/NFA & 3.9 & 3.2 & 2.70 & 8.1 & 58 \\
\hline
\end{tabular}

The reducibility of the catalysts has been also studied by temperature programmed reduction (TPR). TPR profile for each catalyst is shown in Figure 7. In general, three large reduction peaks can be delimited in the reduction profiles for all catalysts. The first reduction peak appears at low reduction temperatures (100$400{ }^{\circ} \mathrm{C}$ ). This peak would correspond to the reduction of nickel with slight interaction with the support (bulk NiO without interaction with the alumina support or with a weak interaction) [64-68]. The second reduction peak appears at intermediates reduction temperatures $\left(400-700{ }^{\circ} \mathrm{C}\right)$ and would correspond to the reduction of nickel with a higher interaction with the alumina support. It would be related with mixtures of $\mathrm{Ni}$ and $\mathrm{Al}$ oxides with high content in nickel [64-68]. Finally, the third peak appears at the higher reduction temperatures $\left(700-900^{\circ} \mathrm{C}\right)$. This peak would correspond with the reduction of nickel with high interaction with the alumina support and would be related with the reduction of nickel aluminate species, $\mathrm{NiAl}_{2} \mathrm{O}_{4}[64-$ 68]. As it can be seen, the sample NiCe/NFA present a TPR profile shifted a high reduction temperatures, suggesting a larger interaction of $\mathrm{Ni}$ with the nanofibered alumina support and justifying the lower size of the metallic nickel particles determined by XRD and TEM for this sample.

Table 2 also shows the percentages of reduced nickel present in the catalysts at $700{ }^{\circ} \mathrm{C}$. This data has been obtained from the TPR profiles. The selection of this temperature to calculate the reducibility is because this is the temperature at which the reduction pretreatment is carried out before the catalytic tests. As it was to be expected, from the high interaction Ni-support, the NiCe/NFA sample presented the lowest percentage of reduced nickel.

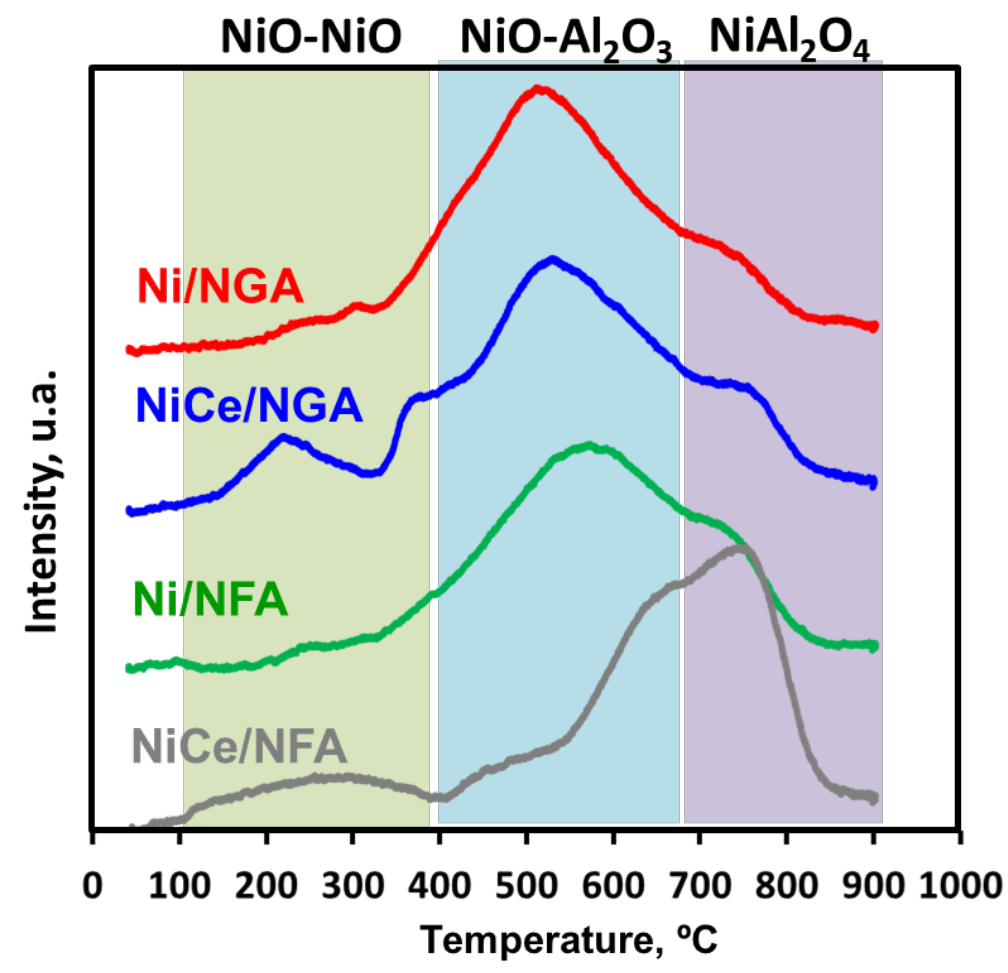

Figure 7. TPR of calcined catalysts studied in this work. 


\subsection{Catalytic activity.}

Catalytic tests have been carried out using a synthetic biogas containing a $\mathrm{CH}_{4} / \mathrm{CO}_{2}$ ratio of 1.5 . Figure 8 shows the $\mathrm{CO}_{2}$ and $\mathrm{CH}_{4}$ conversion values obtained for the four synthesized catalysts in the dry reforming of biogas. Thermodynamic data for $\mathrm{CO}_{2}$ and $\mathrm{CH}_{4}$ conversion is also shown in this figure with black dashed lines [69]. When the samples containing only $\mathrm{Ni}$ are compared (Ni/NGA and Ni/NFA) it can be seen that the catalyst based on nanofibered alumina (Ni/NFA) exhibits a better catalytic activity with higher conversion values for $\mathrm{CO}_{2}$ and $\mathrm{CH}_{4}$, especially at low reaction temperatures $\left(600-700^{\circ} \mathrm{C}\right)$. These results are in concordance with lower size of the metallic nickel particles present in this sample and with its higher active metal surface area determined by $\mathrm{H}_{2}$-Chemisorption. The nanofibered morphology of the alumina support could be considered the final responsible of the higher catalytic activity exhibited by this sample Ni/NFA because its particular morphology would be promoting the formation of metallic nickel particles of lower size and larger active metal surface area. When the samples with and without $\mathrm{Ce}$ are compared (Ni/NGA-NiCe/NGA and Ni-NFA-NiCe/NFA) an improvement in the catalytic activity is observed for the samples containing $\mathrm{Ce}$. The Ce presence seems to have a similar effect than that observed for the nanofibered morphology, favoring the dispersion of metallic $\mathrm{Ni}$ and allowing the formation of smaller metallic particles, what would justify the observed improvement in the catalytic performance [42]. Finally, it is important to note that the sample containing Ni-Ce supported on nanofibered alumina (NiCe/NFA) presents the highest catalytic activity, which can be explained by the combination of the positive effects of nanofibered morphology and presence of Ce. Thus, combined effect dues to morphology and Ce presence seem to be critical in the preparation of dry reforming catalysts with improved catalytic activity and this effect seem to be higher than the effect that the morphology and Ce show separately.
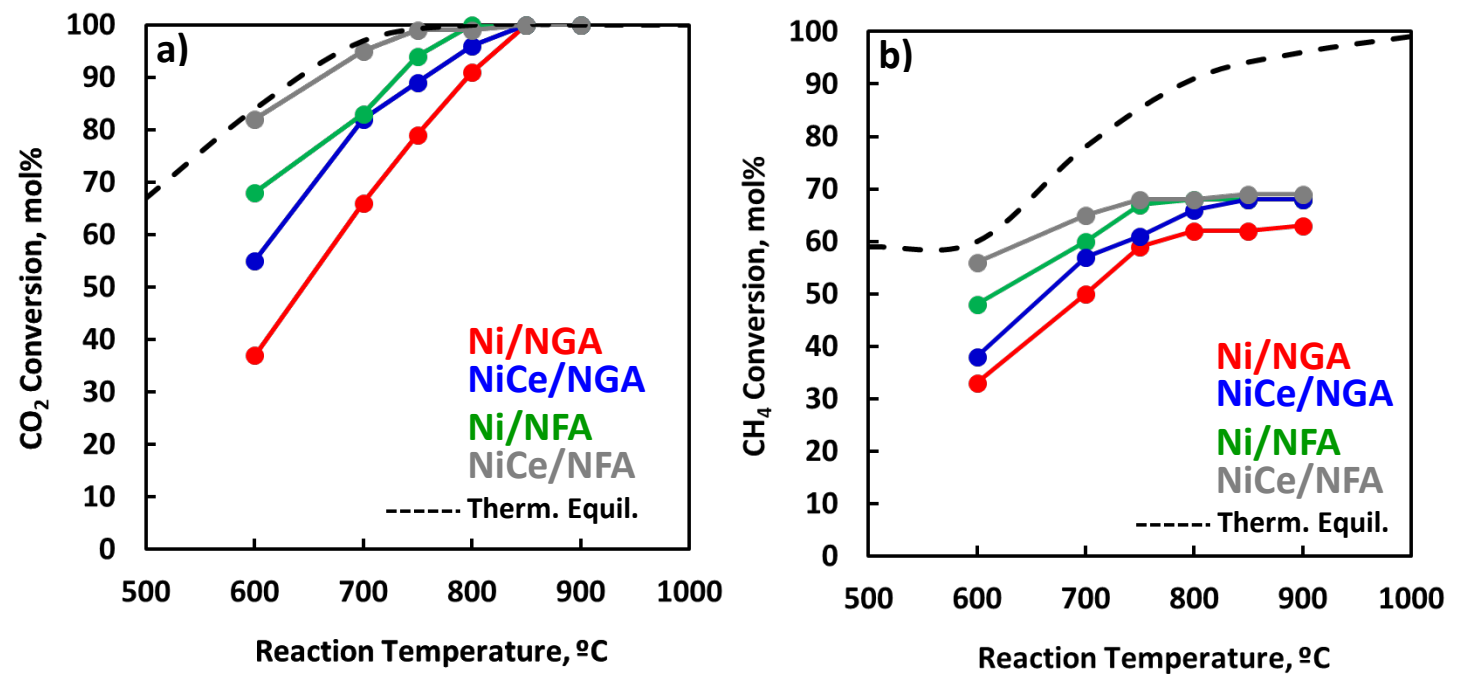

Figure 8. Variation of the $\mathrm{CO}_{2}$ (a) and $\mathrm{CH}_{4}$ (b) conversions with reaction temperature for the catalysts studied in this work. Reaction conditions: $\mathrm{CH}_{4} / \mathrm{CO}_{2}=1.5$, GHSV $=1000 \mathrm{~h}^{-1}$ and atmospheric pressure. Black dashed lines correspond to the thermodynamic equilibrium [69].

$\mathrm{H}_{2}$ and $\mathrm{CO}$ were the only obtained products in the dry reforming reaction. $\mathrm{The}_{2} \mathrm{H}_{2} / \mathrm{CO}$ molar ratio versus temperature reaction is shown in Figure 9. This ratio increases with the reaction temperature, achieving values of 1 at high reaction temperatures, when the $\mathrm{CO}_{2}$ conversion is completed. Similar $\mathrm{H}_{2} / \mathrm{CO}$ molar ratios were found for all the catalysts, indicating that the nanofibered morphology or the presence of $\mathrm{Ce}$ have not a relevant effect on the catalytic selectivity, at least at the reactions conditions here studied. 


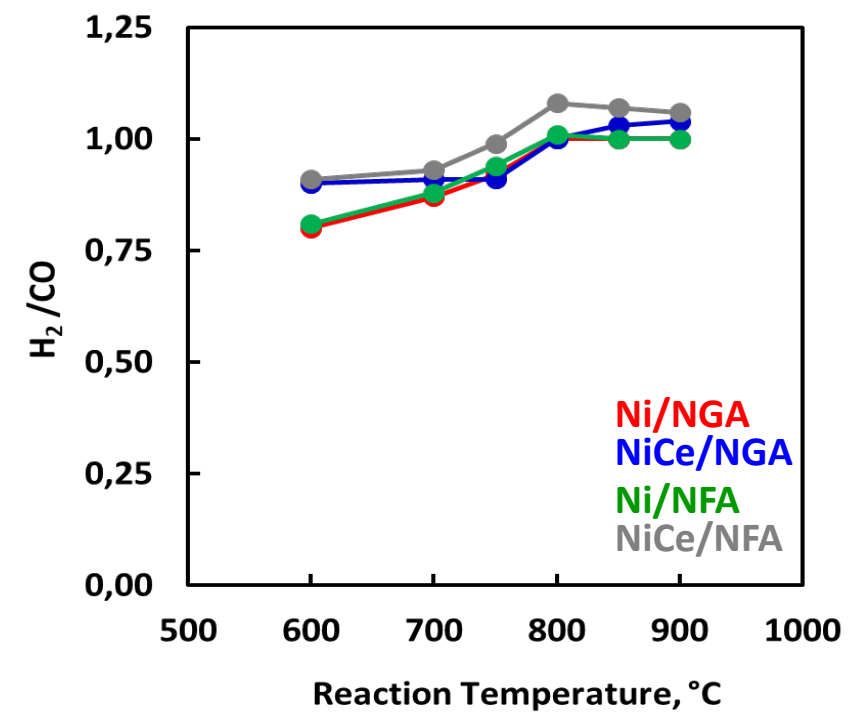

Figure 9. Variation of the $\mathrm{H}_{2} / \mathrm{CO}$ ratio with the reaction temperature for the catalysts studied in this work. Reaction conditions: $\mathrm{CH}_{4} / \mathrm{CO}_{2}=1.5, \mathrm{GHSV}=1000 \mathrm{~h}^{-1}$ and atmospheric pressure.

\subsection{Catalytic deactivation.}

As it was mentioned in the introduction part deactivation is one of the most important problem of the dry reforming catalysts. In order to know the modification of the catalysts here studied during the dry reforming reaction they were characterized after reaction by XRD and elemental analysis. X-ray diffraction pattern of used catalysts is shown in Figure 10. As it can be seen the spent catalysts present the same phases than those observed before reaction: aluminum oxide [JCPDS 00-001-1303] and metallic nickel [JCPDS 03065-0380]. Nevertheless, one more phase at $2 \theta=26.347^{\circ}$ is observed, which corresponds to deposited carbon [JCPDS 00-001-0640]. This fact indicates that during the reaction coke is being deposited in the catalysts, which would indicate that deactivation is occurring. The amount of coke in used catalysts has been determined by elemental analysis (Table 3). As it can be seen a decreasing of the deposited coke were observed when nanofibered alumina is used as support or when Ce is present. Again, the morphology of the support and the presence of Ce seems to have separately a positive influence. However, the combination of both effects seem to entail the largest difference, being the lowest amounts of coke produced by the catalyst with $\mathrm{Ni}$ and $\mathrm{Ce}$ supported on nanofibered alumina.
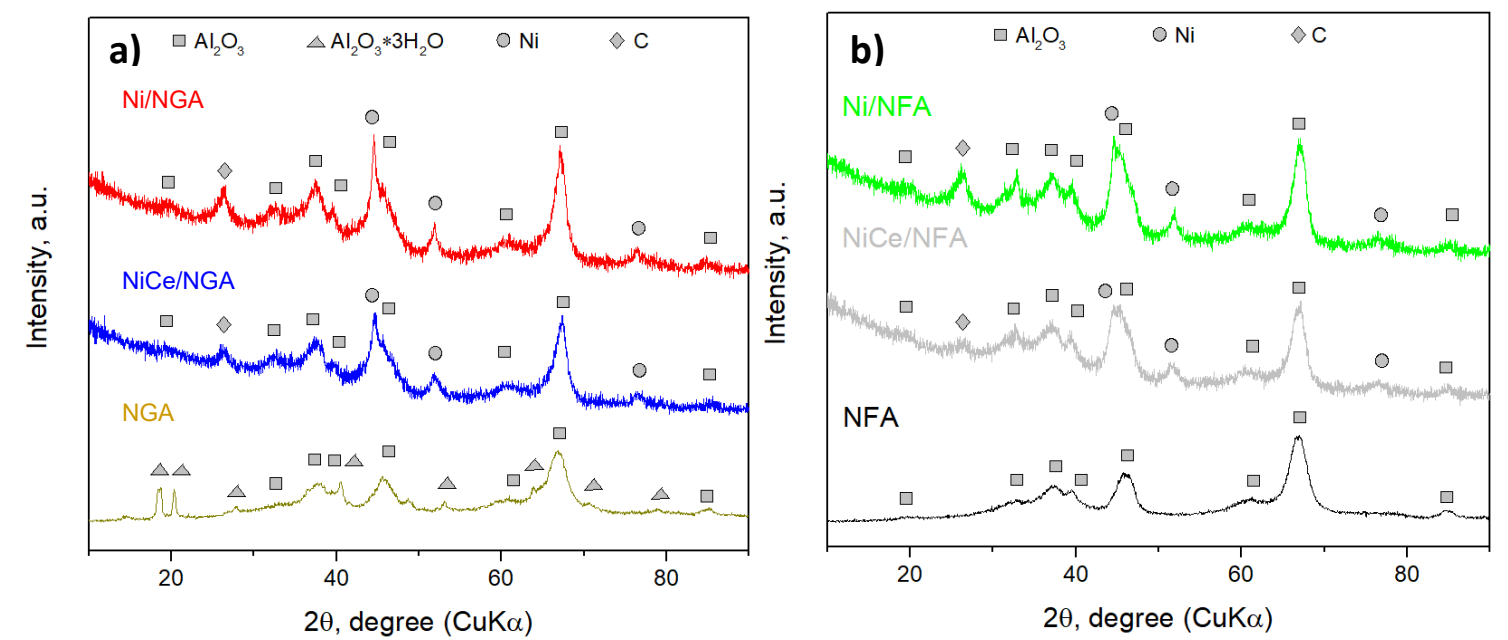

Figure 10. XRD of the used catalyst studied in the dry reforming of simulated biogas. a) XRD of used $\mathrm{Ni} / \mathrm{NGA}, \mathrm{NiCe} / \mathrm{NGA}$ and their corresponding NGA support. b) XRD of used Ni/NFA, NiCe/NFA and their NFA support 
Together with deposition of coke the sinterization of metallic particles is another important parameter affecting the deactivation of dry reforming catalysts. Table 3 shows the size of the metallic nickel particles before and after reaction determined by XRD and the level of sinterization. As it can be seen all the catalysts suffer sinterization during reaction. However, sinterization occurs in a shorter extension in the samples containing $\mathrm{Ce}$. As it has been already reported in literature the incorporation of Ce favors the dispersion of $\mathrm{Ni}$ catalysts with strong metal-support interactions and allows the retention of small Ni particle size, improving the stability of the metallic particles against sintering and inhibits the carbon formation [42]. Similar effect is detected for the nanofibered morphology since a decreasing in the sinterization level is also observed.

Table 3. Crystallite size of metallic nickel particles determined by XRD in the fresh and spent catalysts, percentage of sinterization and $\mathrm{C}$ deposition after reaction for the catalysts studied in this work.

\begin{tabular}{lcccc}
\hline Sample & $\mathbf{N i}^{\mathbf{0}}, \mathbf{X R D}_{\text {AR }}(\mathbf{n m})$ & $\mathbf{N i}^{\mathbf{0}}, \mathbf{X R D}_{\text {BR }}(\mathbf{n m})$ & Sintering $\mathbf{\%}^{(\mathbf{1})}$ & $\mathbf{C}$ deposition, wt.\% \\
\hline Ni/NGA & 10.4 & 7.7 & 35.0 & 10.1 \\
NiCe/NGA & 9.1 & 7.3 & 24.6 & 8.7 \\
Ni/NFA & 6.2 & 5.5 & 12.7 & 7.2 \\
NiCe/NFA & 4.3 & 3.9 & 10.2 & 2.9 \\
\hline \multicolumn{1}{c}{$\quad$ Sinterization }
\end{tabular}
reaction $\left.\left(\mathrm{XRD}_{\mathrm{BR}}\right)\right\} * 100$

The contribution of the morphology and Ce addition to sintering and coke deposition has been studied in deeper. Table 4 shows the contribution of each effect expressed as percentages. In one intent to quantify contribution of the morphology, catalysts containing the same metals have been compared. Thus, catalysts containing only $\mathrm{Ni}$ have been compared by one hand (Ni/NGA and Ni/NFA) and by the other the catalysts containing $\mathrm{Ni}-\mathrm{Ce}$ ( $\mathrm{NiCe} / \mathrm{NGA}$ and $\mathrm{NiCe} / \mathrm{NFA}$ ). To determine the Ce contribution the catalysts prepared with NGA support was compared by one hand (Ni/NGA and NiCe/NGA) and by other the catalysts prepared with NFA (Ni/NFA and NiCe/NFA). Comparing these pairs of catalysts, the morphology and Ce contributions can be determined separately. Finally, the combined contribution of both, morphology and $\mathrm{Ce}$, has been determined comparing the samples Ni/NGA and NiCe/NFA.

As it can be seen in Table 3 the major contributor to avoid the sinterization of the metallic nickel particles and coke deposition is clearly the morphology. Nevertheless, for carbon deposition the differences between morphology and Ce are lower, specifically for the catalyst prepared with NFA, where the Ce contribution is close to the morphology contribution ( $59.7 \%$ and $66.7 \%$, respectively). Thus, it is clear that nanofibered morphology is a strong contributor in the preparation of alumina-based catalysts with improved stability against sinterization and carbon deposition. On the other hand, the major contribution of the Ce seems to be more related to the coke deposition, which was clearly lower when Ce is supported on nanofibered alumina. Finally, when the combined contribution is considered it can be seen it is very similar for both, morphology and Ce presence. However, the obtained values cannot be explained by the single addition of the individual contribution, suggesting that the combination of both effects would need a more detailed study. 
Table 4. Morphology and Ce contributions for sintering and carbon deposition. Percentage of individual and combined contributions.

\begin{tabular}{|c|c|c|c|c|c|c|}
\hline \multirow[b]{2}{*}{ Sample } & \multicolumn{3}{|c|}{ Sintering, $\%^{(\mathbf{a})}$} & \multicolumn{3}{|c|}{ C deposition, wt.\%(b) } \\
\hline & $\begin{array}{c}\text { Support } \\
\text { effect }\end{array}$ & Ce effect & $\begin{array}{c}\text { Combined } \\
\text { effect }\end{array}$ & $\begin{array}{c}\text { Support } \\
\text { effect }\end{array}$ & Ce effect & $\begin{array}{c}\text { Combined } \\
\text { effect }\end{array}$ \\
\hline Ni/NGA & - & - & - & - & - & - \\
\hline NiCe/NGA & - & 29.7 & - & - & 13.9 & - \\
\hline Ni/NFA & - & - & - & - & - & - \\
\hline NiCe/NFA & - & 19.7 & & - & 59.7 & \\
\hline Ni/NGA & - & - & - & - & - & - \\
\hline Ni/NFA & 63.7 & - & - & 28.7 & - & - \\
\hline NiCe/NGA & - & - & - & - & - & - \\
\hline $\mathrm{NiCe/NFA}$ & 58.5 & - & - & 66.7 & - & - \\
\hline Ni/NGA & - & - & - & - & - & - \\
\hline NiCe/NFA & - & - & 70.9 & - & - & 71.3 \\
\hline
\end{tabular}

The values of these table have been calculated from data of Table 3 as follow:

(a) Sintering: \{[Sintering \% of first catalyst-sintering \% of second catalyst] /sintering \% of first catalyst $\} * 100$

(b) $\mathrm{C}$ deposition: $\{[\mathrm{C}$ deposition on first catalyst- $\mathrm{C}$ deposition on second catalyst $] / \mathrm{C}$ deposition on first catalyst $\} * 100$

\subsection{Catalytic stability test.}

From the before studies, it has been found that NiCe/NFA catalyst exhibits the highest catalytic activity with the lowest metal sintering and carbon deposition. It has been seen that this sample combines the positive effects of the nanofibered morphology of alumina support and the presence of Ce. Thus, it is an excellent candidate for long-term stability tests as previous step for its scaled up and industrial application. Stability test has been carried out at $750{ }^{\circ} \mathrm{C}, \mathrm{CH}_{4}: \mathrm{CO}_{2}=55: 45$ and $\mathrm{GHSV}=1000 \mathrm{~h}^{-1}$. Figure 11 shows the $\mathrm{CO}_{2}$ and $\mathrm{CH}_{4}$ conversion and $\mathrm{H}_{2}$ and $\mathrm{CO}$ selectivity values with reaction time for the dry reforming of simulated biogas. As it can be seen the conversion values fall down very fast in the first 20 hours (from $95 \%$ to $87 \%$ for $\mathrm{CO}_{2}$ ). Later a very low deactivation is detected with a loss of activity under $2 \%$ during the following 35 hours.

Regeneration of the catalyst was also carried out after 55 hours of reaction time in air at $600{ }^{\circ} \mathrm{C}$ for $2 \mathrm{~h}$. As it can be seen in Figure 11 the initial catalytic activity is completely recovered, detecting now a lower initial rate of deactivation and, in general, a lower deactivation rate during the following 45 hours. The results obtained in the catalytic stability test, together with the regeneration test, suggest that this catalytic material, based on nanofibered alumina promoted with $\mathrm{Ni}$ and $\mathrm{Ce}$ (NiCe/NFA), presents an excellent stability with reaction time and after regeneration step, offering a high potential to be scaled up and applied at industrial level. 


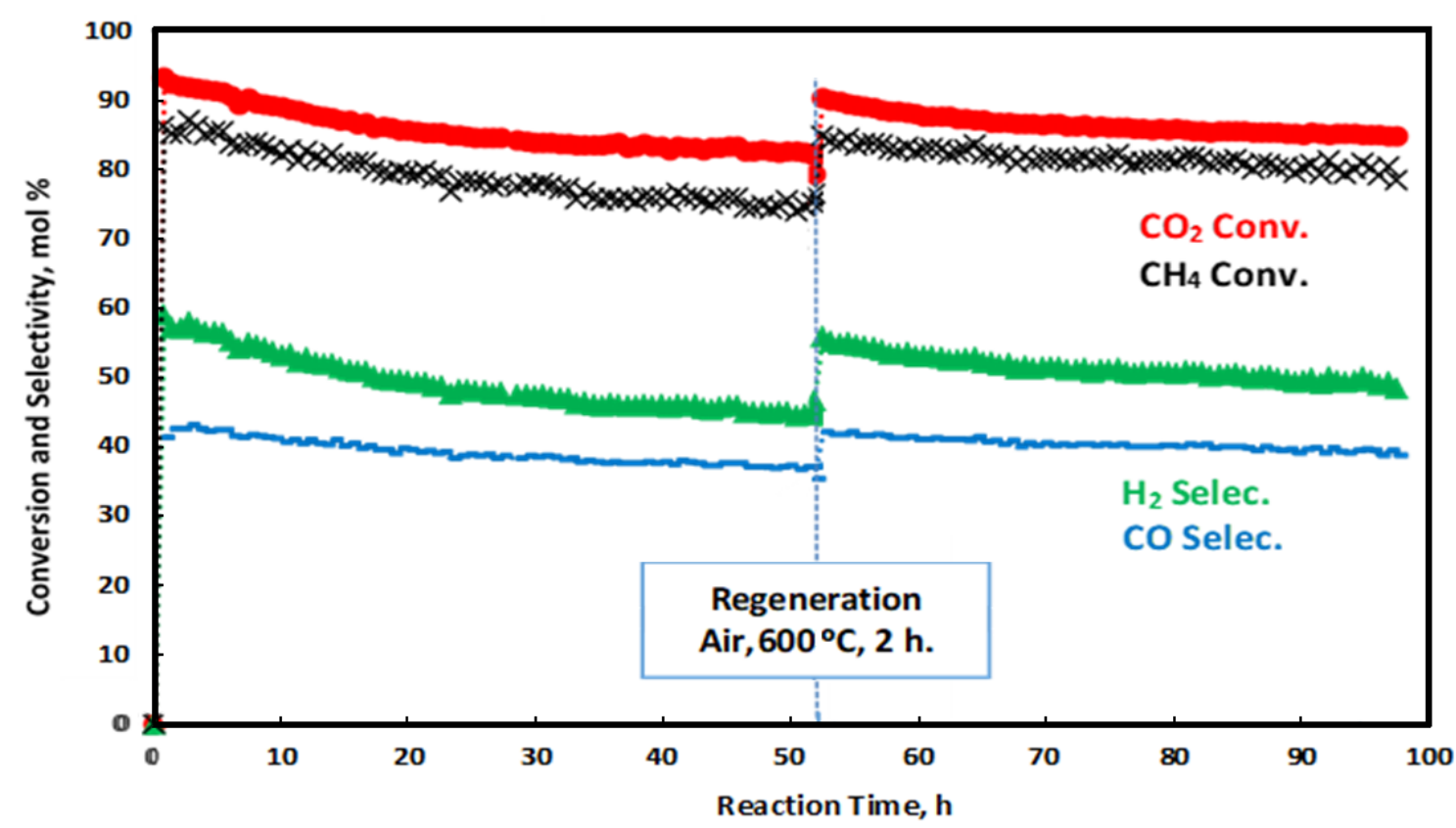

Figure 11. $\mathrm{CO}_{2}$ and $\mathrm{CH}_{4}$ conversion and $\mathrm{H}_{2}$ and $\mathrm{CO}$ selectivity values with the reaction time for the dry reforming of simulated biogas using the $\mathrm{NiCe} / \mathrm{NFA}$ catalyst. Reaction conditions: $750{ }^{\circ} \mathrm{C}, \mathrm{CH}_{4}: \mathrm{CO}_{2}=55: 45$ $(\mathrm{mol} / \mathrm{mol})$ and $\mathrm{GHSV}=1000 \mathrm{~h}^{-1}$.

According to the results presented in this study the excellent catalytic performance exhibited by the $\mathrm{NiCe} / \mathrm{NFA}$ sample seem to be related to combined effect of the nanofibered morphology of the alumina support and the presence of $\mathrm{Ce}$, which allow the preparation of a nickel-based catalyst with smaller metallic Ni particles and with higher resistance against sinterization and coke deposition.

\section{Conclusions.}

Catalysts based on nanograiny (NGA) and nanofibered $\gamma$-alumina (NFA) support promoted with Ni and NiCe has been prepared with high catalytic activity and stability in the dry reforming of synthetic biogas. For the first time, the separated and combined effects of the support morphology and Ce presence in Ni-based alumina catalysts have been studied in the dry reforming of methane. It has been shown that the alumina morphology has an important influence in the preparation of alumina-based catalysts with high catalytic activity. The morphology effect seem to be related to the mesoporosity and higher pore diameter presented by the nanofibered alumina, which would be improving the diffusion of the nickel and cerium precursors during the impregnation step, favoring the dispersion of the metallic particles and the formation of particles of smaller size. On the other hand, the presence of Ce has been proved that has similar effects. However, when morphology and Ce effects are studied separately in the sinterization of the Ni metallic particles and coke deposition, it has been seem that morphology has a larger influence than Ce, decreasing in a higher extension sinterization and carbon formation. The presence of Ce only has a similar effect than morphology in the coke deposition, when $\mathrm{Ce}$ is supported on nanofibered alumina. When morphology and Ce effects are combined an additive effect is not clearly found. Thus, more detailed studies are needed for a better understanding and explanation of this behavior. The best catalytic results were obtained with the NiCe/NFA catalyst. Thus, a stability study with reaction time was carried out, finding a low rate of deactivation during the steady state after 55 hours of reaction time $(<2 \%)$. It was also found that the initial catalytic activity can be completely recovered after a regeneration in air at $600{ }^{\circ} \mathrm{C}$. The results here shown suggest that the catalytic material based on nanofibered alumina promoted with $\mathrm{Ni}$ and $\mathrm{Ce}(\mathrm{NiCe} / \mathrm{NFA})$ presents an excellent potential to be scaled up and applied at industrial level. 


\section{Acknowledgements}

Thank you to the Spanish Government (Project RTI2018-102161-I00) and Generalitat Valenciana (PROMETEO/2018/006 grant) for the financial support. The support of the microscopy service at Universitat Politècnica de València (UPV) for the SEM and TEM analysis is also recognized.

\section{References}

[1] Sun Q, Li H, Yan J, Liu L, Yu Z, Yu X. Selection of appropriate biogas upgrading technology-a review of biogas cleaning, upgrading and utilisation. Renewable and Sustainable Energy Reviews. 2015;51:521-32.

[2] Bharathiraja B, Sudharsanaa T, Bharghavi A, Jayamuthunagai J, Praveenkumar R. Biohydrogen and Biogas - An overview on feedstocks and enhancement process. Fuel. 2016;185:810-28.

[3] Ahmadi Moghaddam E, Ahlgren S, Hulteberg C, Nordberg Å. Energy balance and global warming potential of biogas-based fuels from a life cycle perspective. Fuel Processing Technology. 2015;132:74-82.

[4] Nahar G, Mote D, Dupont V. Hydrogen production from reforming of biogas: Review of technological advances and an Indian perspective. Renewable and Sustainable Energy Reviews. 2017;76:1032-52.

[5] Gao Y, Jiang J, Meng Y, Yan F, Aihemaiti A. A review of recent developments in hydrogen production via biogas dry reforming. Energy Conversion and Management. 2018;171:133-55.

[6] Neuling U, Kaltschmitt M. Techno-economic and environmental analysis of aviation biofuels. Fuel Processing Technology. 2018;171:54-69.

[7] Serrano-Lotina A, Daza L. Long-term stability test of Ni-based catalyst in carbon dioxide reforming of methane. Applied Catalysis A: General. 2014;474:107-13.

[8] Özkara-Aydınoğlu Ş, Özensoy E, Aksoylu AE. The effect of impregnation strategy on methane dry reforming activity of Ce promoted Pt/ZrO2. International Journal of Hydrogen Energy. 2009;34:9711-22.

[9] Serrano-Lotina A, Daza L. Highly stable and active catalyst for hydrogen production from biogas. Journal of Power Sources. 2013;238:81-6.

[10] Taufiq-Yap YH, Sudarno, Rashid U, Zainal Z. CeO2-SiO2 supported nickel catalysts for dry reforming of methane toward syngas production. Applied Catalysis A: General. 2013;468:35969.

[11] Charisiou ND, Douvartzides SL, Siakavelas GI, Tzounis L, Sebastian V, Stolojan V, et al. The Relationship between Reaction Temperature and Carbon Deposition on Nickel Catalysts Based on Al2O3, ZrO2 or SiO2 Supports during the Biogas Dry Reforming Reaction. Catalysts. 2019;9.

[12] Dias JAC, Assaf JM. Autoreduction of promoted Ni/ $\mathrm{Y}$-Al2O3 during autothermal reforming of methane. Journal of Power Sources. 2005;139:176-81.

[13] Derk AR, Moore GM, Sharma S, McFarland EW, Metiu H. Catalytic Dry Reforming of Methane on Ruthenium-Doped Ceria and Ruthenium Supported on Ceria. Topics in Catalysis. 2014;57:118-24.

[14] Frontera P, Macario A, Aloise A, Antonucci PL, Giordano G, Nagy JB. Effect of support surface on methane dry-reforming catalyst preparation. Catalysis Today. 2013;218-219:18-29.

[15] Luengnaruemitchai A, Kaengsilalai A. Activity of different zeolite-supported Ni catalysts for methane reforming with carbon dioxide. Chemical Engineering Journal. 2008;144:96-102.

[16] Kim HY, Park J-N, Henkelman G, Kim JM. Design of a Highly Nanodispersed Pd-MgO/SiO2 Composite Catalyst with Multifunctional Activity for CH4 Reforming. ChemSusChem. 2012;5:1474-81. 
[17] Chen X, Jiang J, Tian S, Li K. Biogas dry reforming for syngas production: catalytic performance of nickel supported on waste-derived SiO2. Catalysis Science \& Technology. 2015;5:860-8.

[18] Kalai DY, Stangeland K, Jin Y, Tucho WM, Yu Z. Biogas dry reforming for syngas production on La promoted hydrotalcite-derived Ni catalysts. International Journal of Hydrogen Energy. 2018;43:19438-50.

[19] Damaskinos CM, Vasiliades MA, Efstathiou AM. The effect of Ti4+ dopant in the $5 \mathrm{wt} \%$ $\mathrm{Ni} / \mathrm{Ce} 1-\mathrm{xTixO2}-\delta$ catalyst on the carbon pathways of dry reforming of methane studied by various transient and isotopic techniques. Applied Catalysis A: General. 2019;579:116-29.

[20] Rosha P, Mohapatra SK, Mahla SK, Dhir A. Catalytic reforming of synthetic biogas for hydrogen enrichment over $\mathrm{Ni}$ supported on $\mathrm{ZnOCeO} 2$ mixed catalyst. Biomass and Bioenergy. 2019;125:70-8.

[21] Moura-Nickel CD, Costa RL, Salvador Ferreira SR, de Fátima Peralta Muniz Moreira R, José HJ. NiY2O3Al2O3 aerogel catalysts with high coke deposition resistance for syngas production by biogas reforming. International Journal of Hydrogen Energy. 2019;44:11861-71.

[22] Roblero JG, Pola-Albores F, Valenzuela MA, Rojas-García E, Ríos-Valdovinos E, ValverdeAguilar $\mathrm{G}$. Ni and Ni3C catalysts supported on mesoporous silica for dry reforming of methane. International Journal of Hydrogen Energy. 2019;44:10473-83.

[23] Charisiou ND, Siakavelas G, Tzounis L, Sebastian V, Monzon A, Baker MA, et al. An in depth investigation of deactivation through carbon formation during the biogas dry reforming reaction for $\mathrm{Ni}$ supported on modified with $\mathrm{CeO} 2$ and $\mathrm{La} 2 \mathrm{O} 3$ zirconia catalysts. International Journal of Hydrogen Energy. 2018;43:18955-76.

[24] Kwon BW, Oh JH, Kim GS, Yoon SP, Han J, Nam SW, et al. The novel perovskite-type Nidoped Sr0.92Y0.08TiO3 catalyst as a reforming biogas $(\mathrm{CH} 4+\mathrm{CO} 2)$ for $\mathrm{H} 2$ production. Applied Energy. 2018;227:213-9.

[25] Sarno C, Luisetto I, Zurlo F, Licoccia S, Di Bartolomeo E. Lanthanum chromite based composite anodes for dry reforming of methane. International Journal of Hydrogen Energy. 2018;43:14742-50.

[26] Zeng YX, Wang L, Wu CF, Wang JQ, Shen BX, Tu X. Low temperature reforming of biogas over K-, Mg- and Ce-promoted Ni/Al2O3 catalysts for the production of hydrogen rich syngas: Understanding the plasma-catalytic synergy. Applied Catalysis B: Environmental. 2018;224:46978.

[27] Kalai DY, Stangeland K, Jin Y, Yu Z. Active and stable hydrotalcite derived Ni catalysts for $\mathrm{CO} 2$ reforming of methane: Comparison with catalysts by incipient wetness. Journal of $\mathrm{CO} 2$ Utilization. 2018;25:346-55.

[28] Károlyi J, Németh $M$, Evangelisti $C$, Sáfrán G, Schay Z, Horváth A, et al. Carbon dioxide reforming of methane over $\mathrm{Ni}-\mathrm{In} / \mathrm{SiO} 2$ catalyst without coke formation. Journal of Industrial and Engineering Chemistry. 2018;58:189-201.

[29] Jabbour K, Saad A, Inaty L, Davidson A, Massiani P, El Hassan N. Ordered mesoporous FeAl2O3 based-catalysts synthesized via a direct "one-pot" method for the dry reforming of a model biogas mixture. International Journal of Hydrogen Energy. 2019;44:14889-907.

[30] Bu K, Kuboon S, Deng J, Li H, Yan T, Chen G, et al. Methane dry reforming over boron nitride interface-confined and LDHs-derived $\mathrm{Ni}$ catalysts. Applied Catalysis B: Environmental. 2019;252:86-97.

[31] Tathod AP, Hayek N, Shpasser D, Simakov DSA, Gazit OM. Mediating interaction strength between nickel and zirconia using a mixed oxide nanosheets interlayer for methane dry reforming. Applied Catalysis B: Environmental. 2019;249:106-15.

[32] Rahemi N, Haghighi M, Babaluo AA, Jafari MF, Estifaee P. Synthesis and physicochemical characterizations of $\mathrm{Ni} / \mathrm{Al} 2 \mathrm{O} 3-\mathrm{ZrO} 2$ nanocatalyst prepared via impregnation method and treated with non-thermal plasma for $\mathrm{CO} 2$ reforming of $\mathrm{CH} 4$. Journal of Industrial and Engineering Chemistry. 2013;19:1566-76. 
[33] Sajjadi SM, Haghighi M, Eslami AA, Rahmani F. Hydrogen production via CO2-reforming of methane over $\mathrm{Cu}$ and $\mathrm{Co}$ doped $\mathrm{Ni} / \mathrm{Al} 2 \mathrm{O} 3$ nanocatalyst: impregnation versus sol-gel method and effect of process conditions and promoter. Journal of Sol-Gel Science and Technology. 2013;67:601-17.

[34] Aghamohammadi S, Haghighi M, Karimipour S. A Comparative Synthesis and Physicochemical Characterizations of Ni/Al2O3\&\#8211;MgO Nanocatalyst via Sequential Impregnation and Sol\&\#8211;Gel Methods Used for CO2 Reforming of Methane. Journal of Nanoscience and Nanotechnology. 2013;13:4872-82.

[35] Therdthianwong S, Siangchin C, Therdthianwong A. Improvement of coke resistance of $\mathrm{Ni} / \mathrm{Al} 2 \mathrm{O} 3$ catalyst in $\mathrm{CH} 4 / \mathrm{CO} 2$ reforming by $\mathrm{ZrO} 2$ addition. Fuel Processing Technology. 2008;89:160-8.

[36] Pompeo F, Nichio NN, Souza MMVM, Cesar DV, Ferretti OA, Schmal M. Study of Ni and Pt catalysts supported on $\alpha-\mathrm{Al} 2 \mathrm{O} 3$ and $\mathrm{ZrO} 2$ applied in methane reforming with $\mathrm{CO} 2$. Applied Catalysis A: General. 2007;316:175-83.

[37] Charisiou ND, Siakavelas G, Papageridis KN, Baklavaridis A, Tzounis L, Avraam DG, et al. Syngas production via the biogas dry reforming reaction over nickel supported on modified with $\mathrm{CeO} 2$ and/or La2O3 alumina catalysts. Journal of Natural Gas Science and Engineering. 2016;31:164-83.

[38] Da Costa-Serra JF, Chica A. Bioethanol steam reforming on Co/ITQ-18 catalyst: Effect of the crystalline structure of the delaminated zeolite ITQ-18. International Journal of Hydrogen Energy. 2011;36:3862-9.

[39] Da Costa-Serra JF, Guil-López R, Chica A. Co/ZnO and Ni/ZnO catalysts for hydrogen production by bioethanol steam reforming. Influence of $\mathrm{ZnO}$ support morphology on the catalytic properties of $\mathrm{Co}$ and $\mathrm{Ni}$ active phases. International Journal of Hydrogen Energy. 2010;35:6709-16.

[40] Fuertes A, Da Costa-Serra JF, Chica A. New Catalysts based on Ni-Birnessite and NiTodorokite for the Efficient Production of Hydrogen by Bioethanol Steam Reforming. Energy Procedia. 2012;29:181-91.

[41] Wang S, Lu GQ. Role of $\mathrm{CeO} 2$ in Ni/CeO2-Al2O3 catalysts for carbon dioxide reforming of methane. Applied Catalysis B: Environmental. 1998;19:267-77.

[42] Tu PH, Le DN, Dao TD, Tran Q-T, Doan TCD, Shiratori Y, et al. Paper-structured catalyst containing $\mathrm{CeO} 2-\mathrm{Ni}$ flowers for dry reforming of methane. International Journal of Hydrogen Energy. 2019.

[43] Charisiou ND, Iordanidis A, Polychronopoulou K, Yentekakis IV, Goula MA. Studying the stability of $\mathrm{Ni}$ supported on modified with $\mathrm{CeO} 2$ alumina catalysts for the biogas dry reforming reaction. Materials Today: Proceedings. 2018;5:27607-16.

[44] Goula MA, Charisiou ND, Siakavelas G, Tzounis L, Tsiaoussis I, Panagiotopoulou P, et al. Syngas production via the biogas dry reforming reaction over $\mathrm{Ni}$ supported on zirconia modified with $\mathrm{CeO} 2$ or La2O3 catalysts. International Journal of Hydrogen Energy. 2017;42:13724-40.

[45] Nguyen TGH, Tran DL, Sakamoto M, Uchida T, Sasaki K, To TD, et al. Ni-loaded (Ce,Zr)O2- $\delta$ dispersed paper-structured catalyst for dry reforming of methane. International Journal of Hydrogen Energy. 2018;43:4951-60.

[46] Italiano C, Balzarotti R, Vita A, Latorrata S, Fabiano C, Pino L, et al. Preparation of structured catalysts with $\mathrm{Ni}$ and $\mathrm{Ni}-\mathrm{Rh} / \mathrm{CeO} 2$ catalytic layers for syngas production by biogas reforming processes. Catalysis Today. 2016;273:3-11.

[47] Chen W, Zhao G, Xue Q, Chen L, Lu Y. High carbon-resistance Ni/CeAlO3-Al2O3 catalyst for $\mathrm{CH} 4 / \mathrm{CO} 2$ reforming. Applied Catalysis B: Environmental. 2013;136-137:260-8.

[48] Kim J-H, Suh DJ, Park T-J, Kim K-L. Effect of metal particle size on coking during CO2 reforming of $\mathrm{CH} 4$ over Ni-alumina aerogel catalysts. Applied Catalysis A: General. 2000;197:191200. 
[49] Arbag $\mathrm{H}$. Effect of impregnation sequence of $\mathrm{Mg}$ on performance of mesoporous alumina supported $\mathrm{Ni}$ catalyst in dry reforming of methane. International Journal of Hydrogen Energy. 2018;43:6561-74.

[50] Chai R, Zhang Z, Chen P, Pan X, Zhao G, Liu Y, et al. From nano-to macro-engineering of LDHs-derived nanocomposite catalysts for harsh reactions. International Journal of Hydrogen Energy. 2017;42:27094-9.

[51] Becerra AM, Castro-Luna AE. AN INVESTIGATION ON THE PRESENCE OF NiAI2O4 IN A STABLE Ni ON ALUMINA CATALYST FOR DRY REFORMING. Journal of the Chilean Chemical Society. 2005;50:465-9.

[52] Medina F, Salagre P, Sueiras J-E, Fierro J-LG. Characterization of several $\gamma$-aluminasupported nickel catalysts and activity for selective hydrogenation of hexanedinitrile. Journal of the Chemical Society, Faraday Transactions. 1994;90:1455-9.

[53] Kiš E, Marinković-Nedučin R, Lomić G, Bošković G, Obadović DŽ, Kiurski J, et al. Structural and textural properties of the NiO 1203 catalyst. Polyhedron. 1998;17:27-34.

[54] Zhang Z, Hu X, Gao G, Wei T, Dong D, Wang Y, et al. Steam reforming of acetic acid over $\mathrm{NiKOH} / \mathrm{Al} 2 \mathrm{O} 3$ catalyst with low nickel loading: The remarkable promotional effects of $\mathrm{KOH}$ on activity. International Journal of Hydrogen Energy. 2019;44:729-47.

[55] Rahmani S, Meshkani F, Rezaei M. Preparation of Ni-M (M: La, Co, Ce, and Fe) catalysts supported on mesoporous nanocrystalline $\mathrm{\gamma}$-Al2O3 for $\mathrm{CO} 2$ methanation. Environmental Progress \& Sustainable Energy. 2019;38:118-26.

[56] Rosha P, Mohapatra SK, Mahla SK, Dhir A. Biogas reforming for hydrogen enrichment by ceria decorated over nickel catalyst supported on titania and alumina. International Journal of Hydrogen Energy. 2018;43:21246-55.

[57] Liu C, Zhou J, Ma H, Qian W, Zhang H, Ying W. Antisintering and High-Activity Ni Catalyst Supported on Mesoporous Silica Incorporated by $\mathrm{Ce} / \mathrm{Zr}$ for $\mathrm{CO}$ Methanation. Industrial \& Engineering Chemistry Research. 2018;57:14406-16.

[58] Liu S-S, Jin Y-Y, Han Y, Zhao J, Ren J. Highly stable and coking resistant Ce promoted Ni/SiC catalyst towards high temperature CO methanation. Fuel Processing Technology. 2018;177:26674.

[59] Da Costa-Serra JF, Navarro MT, Rey F, Chica A. Bioethanol steam reforming on Ni-based modified mordenite. Effect of mesoporosity, acid sites and alkaline metals. International Journal of Hydrogen Energy. 2012;37:7101-8.

[60] Alarcón A, Guilera J, Díaz JA, Andreu T. Optimization of nickel and ceria catalyst content for synthetic natural gas production through $\mathrm{CO} 2$ methanation. Fuel Processing Technology. 2019;193:114-22.

[61] Liang C, Hu X, Wei T, Jia P, Zhang Z, Dong D, et al. Methanation of CO2 over Ni/Al2O3 modified with alkaline earth metals: Impacts of oxygen vacancies on catalytic activity. International Journal of Hydrogen Energy. 2019;44:8197-213.

[62] Sangnikul P, Phanpa C, Xiao R, Zhang H, Reubroycharoen P, Kuchonthara P, et al. Role of copper- or cerium-promoters on $\mathrm{NiMo} / \mathrm{Y}-\mathrm{Al} 2 \mathrm{O} 3$ catalysts in hydrodeoxygenation of guaiacol and bio-oil. Applied Catalysis A: General. 2019;574:151-60.

[63] Cullity BD. Elements of X-ray Diffraction. In: Company AWP, editor.1956. p. 261-2.

[64] Kim P, Joo JB, Kim H, Kim W, Kim Y, Song IK, et al. Preparation of Mesoporous Ni-alumina Catalyst by One-step Sol-gel Method: Control of Textural Properties and Catalytic Application to the Hydrodechlorination of o-dichlorobenzene. Catalysis Letters. 2005;104:181-9.

[65] Yaakob Z, Bshish A, Ebshish A, Tasirin MS, Alhasan HF. Hydrogen Production by Steam Reforming of Ethanol over Nickel Catalysts Supported on Sol Gel Made Alumina: Influence of Calcination Temperature on Supports. Materials. 2013;6.

[66] Mierczynski P, Mierczynska A, Ciesielski R, Mosinska M, Nowosielska M, Czylkowska A, et al. High Active and Selective Ni/CeO2-Al2O3 and Pd-Ni/CeO2-Al2O3 Catalysts for Oxy-Steam Reforming of Methanol. Catalysts. 2018;8. 
[67] Sangsong S, Ratana T, Tungkamani S, Sornchamni T, Phongaksorn M. Effect of CeO2 loading of the Ce-Al mixed oxide on ultrahigh temperature water-gas shift performance over Ce-Al mixed oxide supported Ni catalysts. Fuel. 2019;252:488-95.

[68] Zhang J, Xu H, Jin X, Ge Q, Li W. Characterizations and activities of the nano-sized Ni/Al2O3 and $\mathrm{Ni} / \mathrm{La}-\mathrm{Al} 2 \mathrm{O} 3$ catalysts for NH3 decomposition. Applied Catalysis A: General. 2005;290:8796.

[69] Nikoo MK, Amin NAS. Thermodynamic analysis of carbon dioxide reforming of methane in view of solid carbon formation. Fuel Processing Technology 2011;92;678-691. 